\title{
Protective antiviral antibody responses in a mouse model of influenza virus infection require $\mathrm{TACl}$
}

\author{
Amaya I. Wolf, ${ }^{1}$ Krystyna Mozdzanowska, ${ }^{1}$ William J. Quinn III, ${ }^{2}$ Michele Metzgar, ${ }^{1}$ Katie L. Williams, \\ Andrew J. Caton, ${ }^{1}$ Eric Meffre, ${ }^{3}$ Richard J. Bram, ${ }^{4}$ Loren D. Erickson,5 David Allman, ${ }^{2}$ \\ Michael P. Cancro, ${ }^{2}$ and Jan Erikson ${ }^{1}$

\begin{abstract}
${ }^{1}$ The Wistar Institute, Philadelphia, Pennsylvania, USA. ${ }^{2}$ University of Pennsylvania, Philadelphia, Pennsylvania, USA. ${ }^{3}$ Department of Immunobiology, Yale University School of Medicine, New Haven, Connecticut, USA. ${ }^{4}$ Mayo Clinic College of Medicine, Rochester, Minnesota, USA. ${ }^{5}$ Department of Microbiology, University of Virginia, Charlottesville, Virginia, USA.
\end{abstract}

\begin{abstract}
Antiviral Abs, for example those produced in response to influenza virus infection, are critical for virus neutralization and defense against secondary infection. While the half-life of $\mathrm{Abs}$ is short, $\mathrm{Ab}$ titers can last a lifetime due to a subset of the Ab-secreting cells (ASCs) that is long lived. However, the mechanisms governing ASC longevity are poorly understood. Here, we have identified a critical role for extrinsic cytokine signals in the survival of respiratory tract ASCs in a mouse model of influenza infection. Irradiation of mice at various time points after influenza virus infection markedly diminished numbers of lung ASCs, suggesting that they are short-lived and require extrinsic factors in order to persist. Neutralization of the TNF superfamily cytokines B lymphocyte stimulator (BLyS; also known as BAFF) and a proliferation-inducing ligand (APRIL) reduced numbers of antiviral ASCs in the lungs and bone marrow, whereas ASCs in the spleen and lung-draining lymph node were surprisingly unaffected. Mice deficient in transmembrane activator and calcium-modulator and cyclophilin ligand interactor (TACI), a receptor for BLyS and APRIL, mounted an initial antiviral B cell response similar to that generated in WT mice but failed to sustain protective Ab titers in the airways and serum, leading to increased susceptibility to secondary viral challenge. These studies highlight the importance of TACI signaling for the maintenance of ASCs and protection against influenza virus infection.
\end{abstract}

\section{Introduction}

Antiviral Abs are critical for host protection and are the basis of successful vaccines. Abs produced in response to influenza infection are crucial for viral neutralization (1) and defense in a secondary viral infection. While the half-life of serum Igs is on the order of weeks (2), specific serum Ab titers can last a lifetime (3). Long-lived Ab-secreting cells (ASCs) and memory $\mathrm{B}$ cells are responsible for $\mathrm{Ab}$ maintenance and can persist for years (reviewed in ref. 4).

Influenza infection in mice induces virus-specific ASCs that are present for several months in various organs, including BM, spleen, lung-draining mediastinal lymph node (medLN), and lungs (5-9). ASC differentiation is governed by changes in gene expression mediated by key transcription factors including B lymphocyte-induced maturation protein 1 (BLIMP-1) (reviewed in ref. 10). ASCs have been subdivided into two subsets based on their lifespan, cell cycle activity, and expression levels of BLIMP-1: shortlived ASCs, representing early rapidly dividing cells with a life expectancy of 3-5 days and lower BLIMP-1 expression; and longlived ASCs, persisting for the lifetime of the mouse, with decreased cell cycle activity and higher levels of BLIMP-1 (2, 11-13). Furthermore, long-lived ASCs survive when exposed to irradiation or treatment with cyclophosphamide, while short-lived ASCs do not $(2,14)$. Both ASC subsets can exist in the spleen of mice; however, long-lived ASCs preferentially localize to the $\operatorname{BM}(2,13,15)$.

Conflict of interest: Richard J. Bram is a co-inventor on patents regarding the TACI gene.

Citation for this article: J Clin Invest. 2011;121(10):3954-3964. doi:10.1172/JCI57362.
The factors responsible for ASC longevity are not well understood. It has been postulated that ASC maintenance is independent of antigen (16), but critically dependent on access to a number of factors that constitute a survival niche (reviewed in ref. 17). These include physical association with BM stromal cells, signals through the Fc receptor $\mathrm{CD} 32$, and soluble factors such as the chemokine CXCL12 and the inflammatory cytokines IL- 6 and TNF- $\alpha$ (18-20). Under conditions of inflammation, survival factors can be upregulated in tissues, leading to ASC recruitment and retention (reviewed in ref. 21). Whether the lung following a respiratory viral infection provides a survival niche for ASCs has yet to be determined. Indeed, reports in the literature are inconclusive regarding ASC persistence in the respiratory tract (RT) following influenza virus infection $(5,9)$.

Recent studies have emphasized the significance of the TNF superfamily members B lymphocyte stimulator (BLyS, also termed BAFF) and a proliferation-inducing ligand (APRIL) as key regulators of ASC survival (22-25). BLyS and APRIL can be produced by activated cells from the myeloid lineage, BM stromal cells, airway epithelial cells, and activated T cells (26-31). In both mice and humans, BLyS and APRIL expression by DCs and macrophages can induce Ig class switching and ASC differentiation (28, 32-35).

BLyS and APRIL bind two receptors, transmembrane activator and calcium-modulator and cyclophilin ligand interactor (TACI) and $\mathrm{B}$ cell maturation antigen (BCMA), while BLyS also binds a third receptor, BLyS receptor 3 (BR3). BCMA is expressed on ASCs in the $\mathrm{BM}$, which are severely reduced in $B C M A^{-/}$mice $(25,36)$. TACI is expressed on follicular B cells and at much higher levels on $\mathrm{CD} 138^{+}$ASCs and marginal zone (MZ) and B1 B cells (36-38). 
A

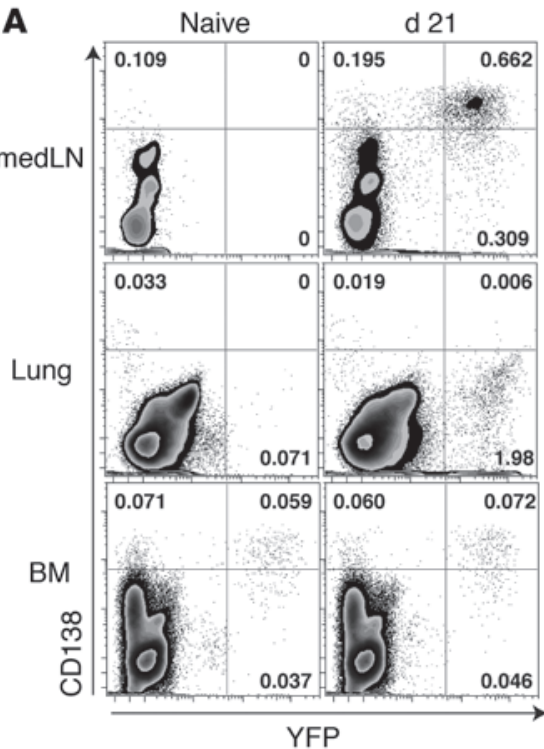

B

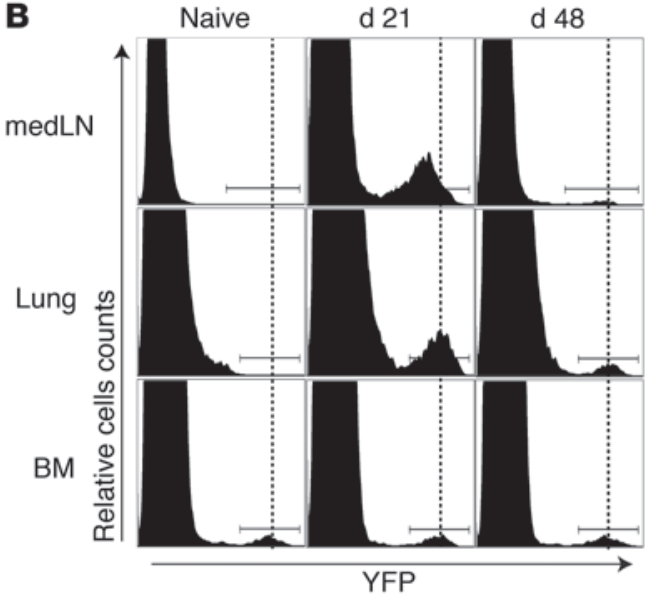

D

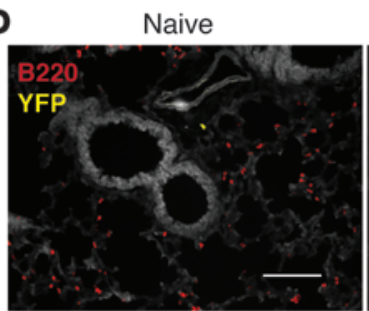

C
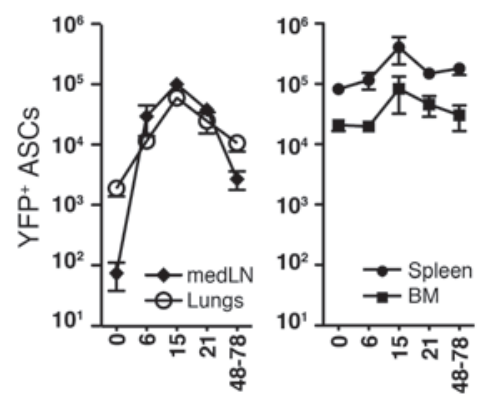

Days after infection

Figure 1

Kinetics of ASCs during influenza virus infection. (A) Naive and influenza virus PR8-infected BLIMP-1-YFP mice (day 21 after infection) were analyzed for YFP ${ }^{+}$CD138 ${ }^{+}$ASCs in lung-draining medLN, lungs, and BM. Cells expressing CD4, CD8, and CD11b were excluded. Dot plots with percentages shown are representative of $n=3-5$ mice from at least 2 independent experiments. (B) Level of YFP expression in ASCs from medLN, lungs and BM isolated from naive and influenza-infected BLIMP-1-YFP mice. Histograms are based on CD4-CD8-CD11b ${ }^{-}$cells and representative of $n=5-7$ mice. (C) Kinetics of YFP+ ASCs during influenza virus infection. Data with mean \pm SEM are representative of $n=3-5$ mice per time point. (D) Immunofluorescence of lungs from naive and infected BLIMP-1-YFP mice stained for B220 (red). Original magnification, $\times 20$, Scale bar: $100 \mu \mathrm{m}$.

TACI has also been detected intracellularly in human DCs (39) and on activated $\mathrm{T}$ cells to varying degrees (reviewed in ref. 40). The role of TACI in isotype switching is controversial: this receptor augments class switching in some cases, as revealed by absence of functional TACI, such as in patients with common variable immunodeficiency disease (CVID) (41-43), but has an inhibitory function in others (44). In vivo studies in $\mathrm{TACI}^{-/-}$mice have found no reduction in Abs produced in $\mathrm{T}$ cell-dependent responses to NP-CGG (4-hydroxy-3-nitrophenylacetate coupled to chicken $\gamma$-globulin), while $\mathrm{T}$ cell-independent $\mathrm{B}$ cell responses to NPFicoll and NP-LPS are impaired (45-48). Others have found that use of TACI-Fc or BCMA-Fc fusion proteins for neutralization of both BLyS and APRIL results in diminished ASCs and Abs to the T cell-dependent antigens NP-CGG and keyhole limpet hemocyanin (KLH), and T cell-independent antigen Pneumovax (49-52).

In this study we address whether ASCs in the RT in comparison to lymphoid organs of influenza-infected mice are long-lived and what signals promote their survival. We demonstrate the importance of extrinsic signals such as the TACI ligands BLyS and APRIL for the longevity of humoral immunity and protection to influenza virus infection.

\section{Results}

Kinetics of ASCs during influenza virus infection. To study ASCs in vivo, we used transgenic BLIMP-1-YFP reporter mice, which express the yellow fluorescent protein (YFP) on a bacterial artificial chromosome under the control of regulatory sequences from the Prdm1 gene locus (53). Analysis of the BM and spleen of naive BLIMP-1YFP mice revealed a small population of cells expressing high levels of YFP, the majority of which coexpressed CD138, consistent with the surface phenotype of ASCs (Figure 1A and Supplemental Figure 1; supplemental material available online with this article; doi:10.1172/JCI57362DS1). YFP ${ }^{+}$ASCs were CD4-CD8-CD11b and expressed varying levels of CD19 depending on the tissue (Supplemental Figure 1A and data not shown). These mice facilitate the study of RT ASCs, since the collagenase digestion required to liberate cells from the lungs reduced cell surface levels of CD138 (Supplemental Figure 1B).

In naive mice, $\mathrm{YFP}^{+}$cells were rare in the lung-draining medLN and in the lungs (Figure 1, A, B, and D). However, after intranasal infection with influenza virus, we observed a significant increase in $\mathrm{YFP}^{+}$ASCs in these organs (10- to 100 -fold), while the number of ASCs in spleen and BM changed little during the course of infection (Figure 1C). Noticeably, lung ASCs exhibited higher YFP expression compared with ASCs in medLN (Figure 1, A and B). Based on previous reports using Blimp-1gfp reporter mice, which correlated higher GFP levels with increasing levels of BLIMP-1 expression and advanced stages of ASC differentiation (11), these results suggest that ASCs in the lungs were further differentiated than ASCs in the medLN. 
A

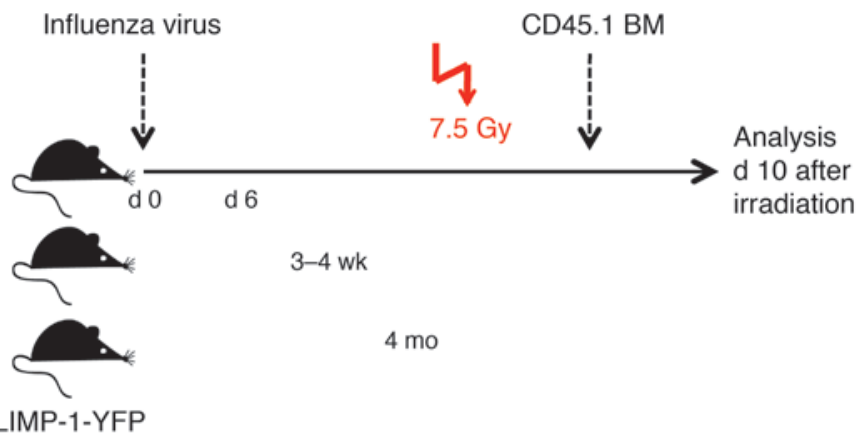

B

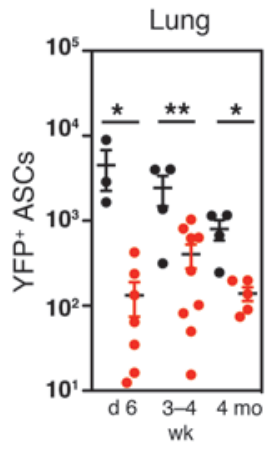

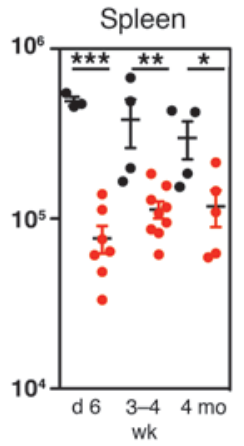

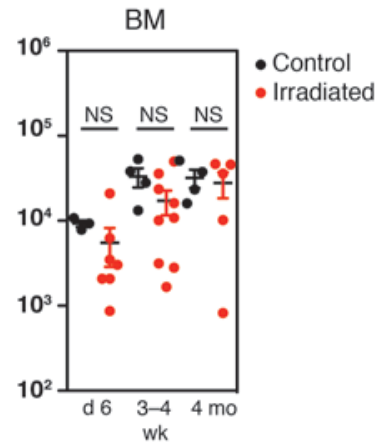

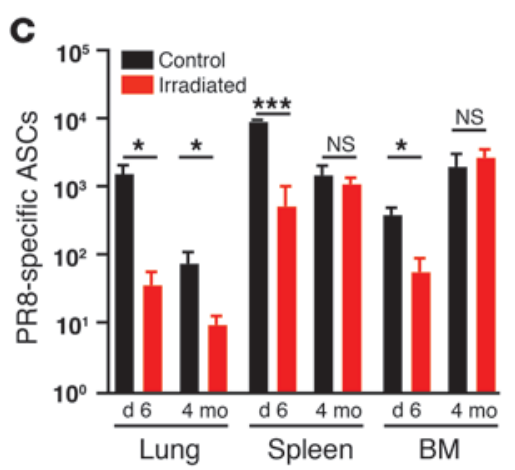

D

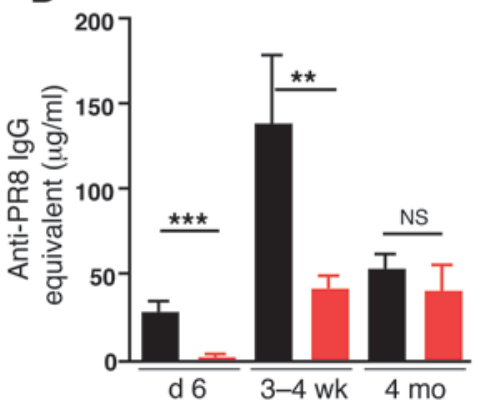

\section{Figure 2}

ASCs in lungs of influenza virus-infected BLIMP-1-YFP mice are sensitive to irradiation. (A) Influenza virus PR8-infected BLIMP-1-YFP mice ( $n=3-9$ mice/group) were subjected to whole-body irradiation ( $7.5 \mathrm{~Gy}$ ) at 6 days, 3-4 weeks, or 4 months p.i. and analyzed 10 days later together with non-irradiated controls. (B) Total YFP+ ASCs in lungs, spleen, and BM were determined by flow cytometry. (C) PR8-specific ASCs were determined by ELISPOT. (D) PR8-specific IgG Ab titers in sera from control and irradiated mice were measured by ELISA. All data with mean \pm SEM represent at least 2 independent experiments. ${ }^{\star} P<0.05,{ }^{* *} P<0.01,{ }^{* \star *} P<0.001$.

The localization of ASCs in tissues was examined using immunofluorescence. In the spleen, $\mathrm{YFP}^{+}$ASCs were detected mainly in extrafollicular foci between $\mathrm{B} 220^{+}$follicles and $\mathrm{CD}^{+}$ $\mathrm{T}$ cell areas in the red pulp (Supplemental Figure 1, C and D). $\mathrm{YFP}^{+}$ ASCs in the lungs of virally infected mice were often associated with $\mathrm{B} 220^{+}$aggregates (Figure 1D), known as inducible bronchusassociated lymphoid tissue (iBALT) (54), and were present for several months after infection.

ASCs in the lungs of influenza-infected mice diminish after irradiation. Long-lived ASCs are resistant to irradiation (2). Thus, we used this measure to determine whether ASCs in the lungs, as well as other sites, of influenza-infected mice were short- or long-lived. BLIMP-1YFP mice were subjected to whole-body irradiation (7.5 Gy) at various times after infection (6 days, 3-4 weeks, or 4 months), subsequently reconstituted with BM from CD45.1 allotypic mice, and analyzed 10 days later (Figure 2A). Splenic $\mathrm{YFP}^{+}$ASCs were sensitive to irradiation (Figure $2 \mathrm{~B}$ ), in contrast to $\mathrm{YFP}^{+} \mathrm{ASC}$ in the $\mathrm{BM}$, indicating that the majority of ASCs are short-lived in the spleen and long-lived in the $\mathrm{BM}$. $\mathrm{YFP}^{+}$ASCs in the lungs were markedly decreased after irradiation, suggesting that they are short-lived.

Virus-specific ASCs as determined by ELISPOT were significantly reduced in all organs after irradiation at day 6 post-infection (p.i.) (Figure 2C). This was consistent with a complete ablation of virusspecific IgG in the serum (Figure 2D). Although irradiation at 3-4 weeks after infection reduced virus-specific serum IgG, the levels were comparable to those in mice at 4 months after infection. Irradiation 4 months after infection had no further effect, indicating that antiviral serum IgG at this time is derived from a pool of irradiation-resistant, long-lived ASCs. Virus-specific ASC numbers in spleen and BM were not diminished by irradiation (Figure 2C), whereas virus-specific ASCs in lungs were significantly reduced.

In anticipation that short-lived ASCs would correspond to proliferating plasmablasts, we determined the cell cycle activity of RT ASCs by BrdU incorporation. Continuous supply of BrdU in the drinking water for 8 days, initiated at either day 8 or day 50 after infection of BLIMP-1-YFP mice, revealed that the turnover of $\mathrm{YFP}^{+}$ ASCs in the lungs, unlike their counterparts in medLN and spleen, was low and resembled the frequency of $\mathrm{BrdU}^{+}$ASCs in the BM 2 months after infection (Supplemental Figure 2, A and B). These results suggest that the maintenance of ASCs in the RT, including virus-specific ASCs, is likely not due to replenishment through proliferation but is instead regulated by survival factors produced by radiation-sensitive sources.

Treatment with TACI-Fc in vivo reduces lung and BM ASCs but does not affect ASCs in medLN and spleen. APRIL and/or BLyS support survival of long-lived BM ASCs $(24,52)$. To address whether these cytokines mediate survival of RT ASCs following infection, we infected BLIMP-1-YFP mice with influenza virus and 35 days later treated them for 2 weeks with TACI-Fc (Figure 3A), which neutralizes both BLyS and APRIL $(50,55)$. TACI-Fc treatment reduced the percentage and number of total $\mathrm{YFP}^{+} \mathrm{ASC}$, including virusspecific ASCs, in lungs and $\mathrm{BM}$. The $P$ value approached significance in spleen $(P=0.0523)$, but strikingly ASCs in medLN were not affected (Figure 3, B and C), suggesting an organ-specific role 
A
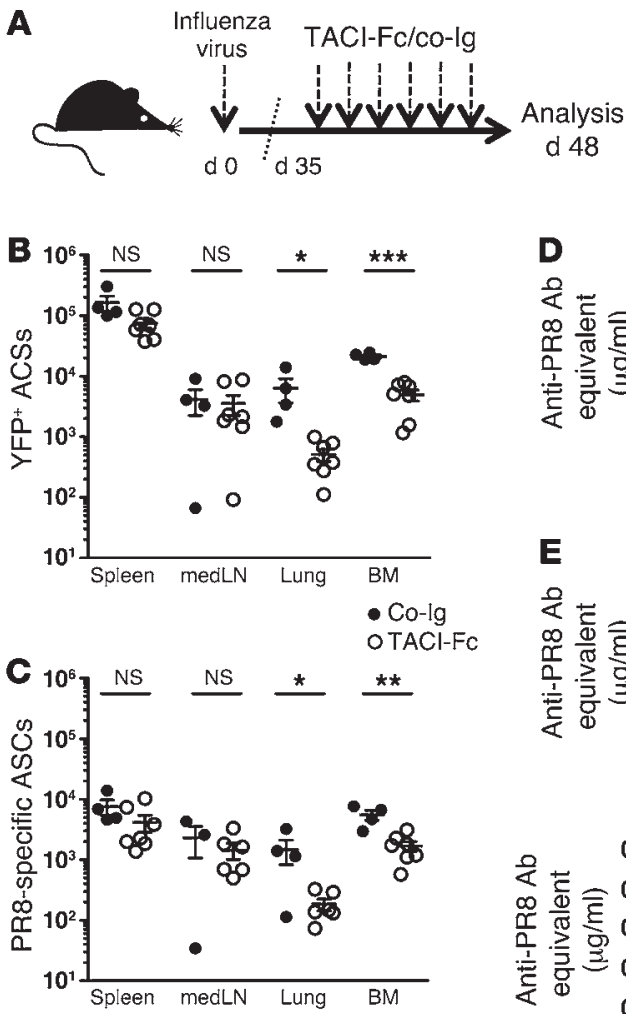
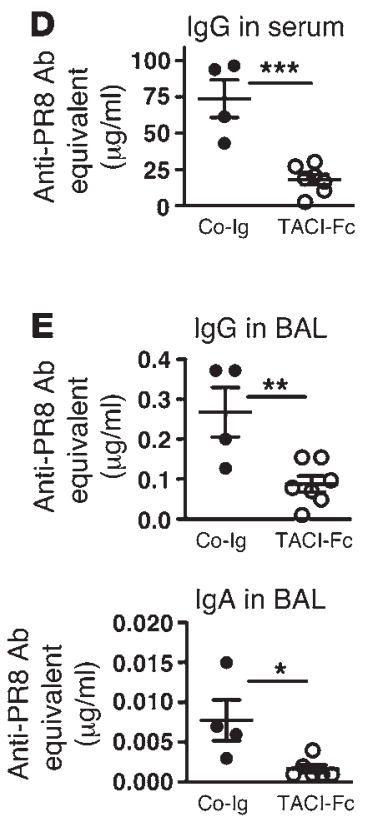

for BLyS and/or APRIL in ASC survival. The decrease in ASCs in $\mathrm{BM}$ and lungs after TACI-Fc treatment was associated with a significant reduction in antiviral serum IgG (Figure 3D), as well as virus-specific IgG and IgA in the BAL (Figure 3E).

To test whether blockade of BLyS alone results in the reduction in antiviral ASCs, we treated BLIMP-1-YFP mice with anti-BLyS (56). CD19+ B cells were significantly reduced in spleen, medLN, and lungs (Supplemental Figure 3A). Although $\mathrm{YFP}^{+}$ASCs were diminished in the spleen, neither total ASCs (Supplemental Figure 3B) nor influenza virus-specific ASC numbers (Supplemental Figure $3 C$ ) in any other of the organs analyzed were affected by neutralization of BLyS, and antiviral Ab titers remained undisturbed in serum and the bronchoalveolar space (Supplemental Figure 3, $\mathrm{D}$ and $\mathrm{E}$ ). Taken together these results show that blockade of BLyS and APRIL, but not BLyS alone, regulates ASC survival in response to influenza virus infection.

We demonstrated that this tissue-specific dependence on BLyS and APRIL was not due to cell-intrinsic differences in receptor expression (Supplemental Figure 4). $\mathrm{YFP}^{+}$ASCs and B220+YFP$B$ cells were sorted from medLN, spleen, lung, and BM of influenza-infected BLIMP-1-YFP mice on day 28 p.i. to determine the level of BR3, TACI, and BCMA mRNA. TACI and BR3 were expressed similarly in all ASCs, while BCMA was elevated in BM ASCs compared with ASCs from the other organs.

Maintenance of influenza-specific Ab titers requires TACI. To address the impact of TACI on antiviral $\mathrm{Ab}$ responses, we infected $\mathrm{TACI}^{-/-}$ and C57BL/6 (WT) mice with influenza virus. The strains had similar viral titers in their lungs at days 3 and 6 p.i., indicating a comparable course of infection (Supplemental Figure 5A). Virusspecific serum IgM peaked at similar levels by day 8 p.i. in WT and $\mathrm{TACI}^{-/-}$mice (Figure 4A). Moreover, no difference in virus-specific

\section{Figure 3}

TACI-Fc treatment of BLIMP-1-YFP mice 1 month after influenza virus infection dramatically reduces virus-specific ASCs. (A) Thirtyfive days after infection with influenza virus PR8, BLIMP-1-YFP mice were treated with $100 \mu \mathrm{g} \mathrm{TACl}-\mathrm{Fc}(n=7$ mice) or human control IgG Ab (co-lg) ( $n=4$ mice) every $2-3$ days until analysis at day 48 p.i. (B) YFP+ ASCs were enumerated in spleen, medLN, lungs, and BM. (C) PR8-specific ASCs were determined by ELISPOT. (D) PR8-specific IgG in serum and (E) PR8-specific IgG and IgA Ab titers in BAL from mice treated with TACI-FC and co-lg were determined by ELISA. All data with mean \pm SEM represent 2 independent experiments. ${ }^{\star} P<0.05,{ }^{\star *} P<0.01,{ }^{\star \star *} P<0.001$.

IgG in the serum was observed until 30 days p.i., when the titers declined significantly in $\mathrm{TACI}^{-/-}$mice. Thus, we conclude that early production of influenza-specific $\operatorname{IgM}$ and $\operatorname{IgG}$ is unperturbed in $\mathrm{TACI}^{-/-}$mice, whereas TACI is required for the maintenance of antiviral IgG.

We next measured the Ig content in the BAL from WT and $\mathrm{TACI}^{-1-}$ mice 8 days and 1 month p.i. As in the serum, we detected no difference in virus-specific IgM in the BAL from either mouse strain on day 8 p.i. However, by day 32 p.i., virus-specific IgG and IgA were 2- and 10-fold reduced in $\mathrm{BAL}$ of $\mathrm{TACI}^{-1-}$ mice, respectively (Figure 4B). The concentration of total IgG in BAL was not different, while total IgA was reduced in $\mathrm{TACI}^{-1-}$ mice (Figure 4C). This finding is consistent with reports that $\mathrm{TACI}^{-/-}$ mice, as compared with WT mice, have similar levels of IgG but reduced $\operatorname{IgA}$ in serum $(45,46)$ and that APRIL deficiency, like TACI deficiency, has a more marked effect on IgA (57).

The early influenza-specific ASC and $C D 8^{+} T$ cell response in the medLN is normal in $\mathrm{TACI}^{-1-}$ mice. To investigate whether early ASC differentiation was affected in $\mathrm{TACI}^{-/-}$mice, we enumerated influenza-specific ASCs 6-8 days p.i. in medLN, where the early B cell activation and ASC differentiation are primarily initiated (58, 59). WT and $\mathrm{TACI}^{-/-}$mice generated comparable frequencies and numbers of antiviral IgM-, IgG-, and IgA-producing ASCs (Figure $5 \mathrm{~A}$ and data not shown), suggesting that early initiation of virusspecific ASCs is TACI independent, consistent with the observed serum Ab levels (Figure 4A).

Others have reported impaired $\mathrm{CD}^{+} \mathrm{T}$ cell activation in the absence of TACI (60). However, $\mathrm{CD}^{+} \mathrm{T}$ cells specific for influenza virus nucleoprotein (NP) were comparable in $\mathrm{WT}$ and $\mathrm{TACI}^{-1-}$ mice at day 8 p.i. (Supplemental Figure 5, B and C).

Survival of ASCs in the BM and lungs, but not in medLN and spleen, is TACI dependent. The reduced virus-specific $A b$ titers in the serum after 1 month p.i. in $\mathrm{TACI}^{-/-}$mice (Figure 4A) coincided with significantly lower numbers of anti-influenza IgG and IgA ASCs in the BM (Figure 5B). A significant reduction in virus-specific IgA ASCs was also observed in the lungs. IgG ASCs were reduced, but the values were not statistically significant at that time point. In contrast, WT and $\mathrm{TACI}^{-/-}$mice harbored similar numbers of virusspecific ASCs in the medLN and spleen, suggesting a TACI-independent pathway of ASC survival in these organs. We showed that these differences were not due to altered total $\mathrm{B}$ cell or germinal center B cell numbers (Supplemental Figure 6, A-C).

Recent work by Bessa et al. has suggested that TACI is required for optimal ASC response after mucosal but not systemic immunization with virus-like particles (34). To test whether TACI-mediated effects on ASC responses to influenza virus are independent of the route of administration, we intravenously injected purified, 


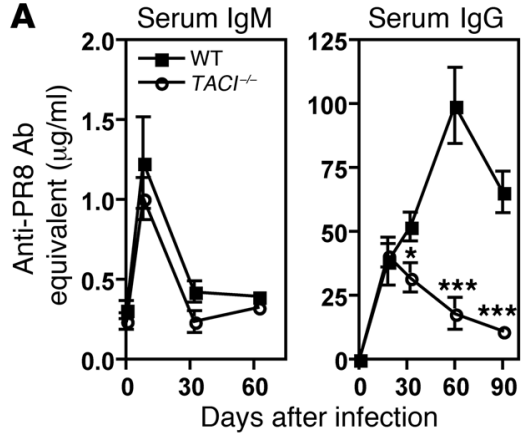

Figure 4

Maintenance of virus-specific Abs to influenza virus requires TACI. (A) Sera from WT and TACl-/- mice were assayed for PR8-specific IgM and IgG by ELISA. Blood samples were collected from naive mice $(n=3$ mice) and on days 8,18 , 33, and 60 p.i. $(n=3-12$ mice per time point). (B) PR8-specific IgM, IgG, and IgA Ab titers in BAL were measured at days 8 and 32-34 p.i. (C) Total IgG and IgA in BAL from WT and TACl-/mice $(n=8-11$ mice/group) were determined (days 32-34 p.i.). Data with mean \pm SEM are representative of at least 2 independent experiments. ${ }^{\star} P<0.05,{ }^{* *} P<0.01,{ }^{* \star} P<0.001$.

non-infectious influenza virus into WT and $\mathrm{TACI}^{-/-}$mice. As with intranasal infection, PR8-specific ASCs were reduced in the BM of $\mathrm{TACI}^{-/-}$mice, while ASC numbers in the spleen were not different (Figure 5C). Virus-specific ASCs were not detectable in lungs with this route of immunization (data not shown). Together, these results indicate that maintenance of virus-specific ASCs in the BM, but not in medLN and spleen, require TACI after both mucosal and systemic administration of influenza virus.

BCMA has been shown to play an important role in survival of BM ASCs (25). To test whether BCMA plays a role in the humoral Ab response to influenza virus infection, we compared $\mathrm{WT}$ and $B C M A^{-1}$ mice. Antiviral serum IgG titers as well as PR8-specific IgG and IgA ASCs were similar in WT and BCMA-deficient mice up to 2 months p.i. (Supplemental Figure 7, A-C), suggesting that BCMA is dispensable for the generation and maintenance of influenza-specific Abs.

$T$ cell help is required for the induction but not maintenance of humoral immunity to influenza virus infection. Previous studies have found that $\mathrm{TACI}^{-/-}$mice have impaired responses to $\mathrm{T}$ cell-independent antigens, whereas no reduction was observed in Abs produced in $\mathrm{T}$ cell-dependent responses (45-48). To test the contribution of $\mathrm{T}$ cell help in the induction and maintenance of the anti-influenza $\mathrm{Ab}$ response, we performed blocking experiments with anti-CD40L $\mathrm{Ab}$ (MR1). WT and $\mathrm{TACI}^{-1}$ - mice were treated with MR1 or hamster Ig control Ab starting at day 3 p.i. every 3 days until day 15 p.i., and serial bleeds were examined for antiviral IgG. Similar to studies in $\mathrm{CD}_{40} 0^{-/}$mice (61), blockade of CD40L resulted in significantly reduced virus-specific serum IgG level in WT mice. An analogous reduction in antiviral IgG was also observed in the serum of $\mathrm{TACI}^{-/}$ mice, suggesting that the antiviral Ab response in both, WT and $\mathrm{TACI}^{-1-}$ mice is dependent in large part on $\mathrm{T}$ cell help (Figure 6A).

To address whether $T$ cell help is required to sustain virus-specific ASCs and Ab titers, we infected BLIMP-1-YFP mice with influenza virus PR8 and after 38 days treated them with anti-CD40L. Treated mice showed a reduction in total $\mathrm{YFP}^{+}$ASCs (Figure 6B) and in germinal center cell numbers (data not shown), but virusspecific ASCs were not affected in any of the organs examined

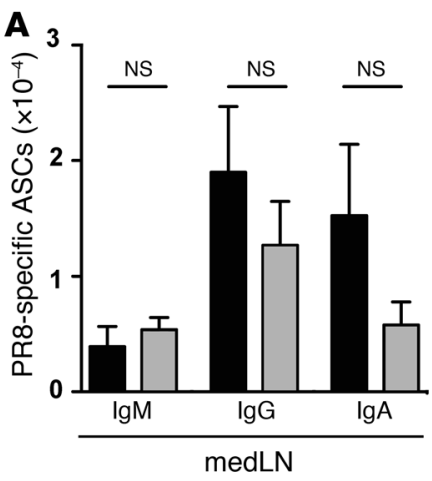

B

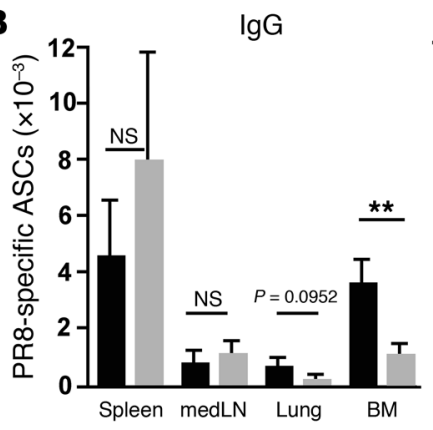

$\lg A$

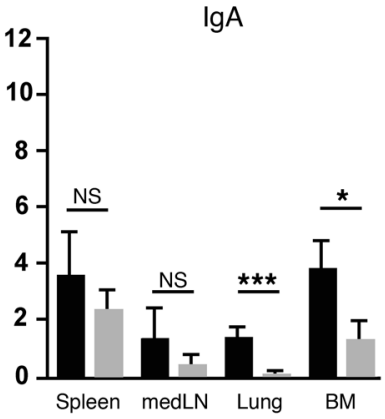

C

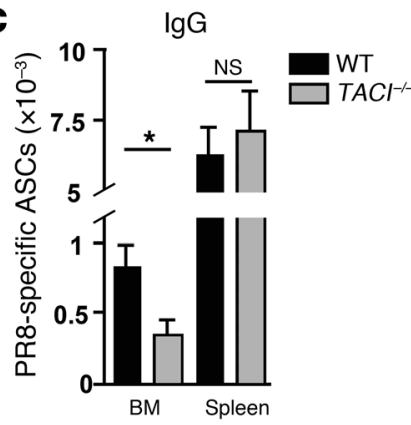

\section{Figure 5}

Maintenance but not early generation of virus-specific ASCs is impaired in $\mathrm{TACl}^{-/-}$mice. (A) MedLNs from WT and TACl ${ }^{-/-}$mice $(n=10-14$ mice/ group) were harvested 6-8 days p.i. and assayed for PR8-specific IgM, IgG, and IgA ASCs by ELISPOT. (B) PR8-specific IgG and IgA ASCs from indicated organs of WT and $\mathrm{TACl}^{-/-}$mice were determined by ELISPOT at days 32-34 p.i. ( $\left.n=5-8 \mathrm{mice} / \mathrm{group}\right)$. (C) WT and TACl/- mice ( $n=5$ mice/group) received 1,000 HAU/100 $\mu$ l purified PR8 virus intravenously, and PR8-specific IgG ASCs were enumerated 30 days later in $\mathrm{BM}$ and spleen. Data with mean \pm SEM are representative of at least 2 independent experiments. ${ }^{\star} P<0.05,{ }^{\star \star} P<0.01,{ }^{\star \star \star} P<0.001$. 
A

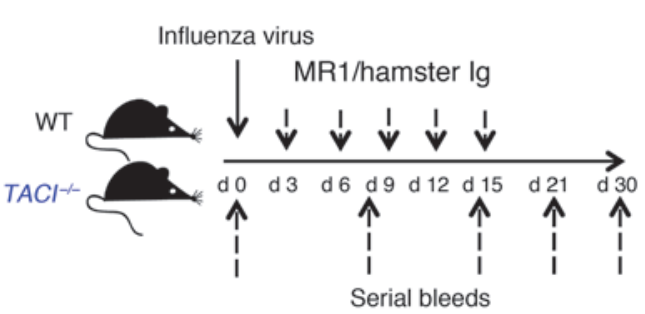

B

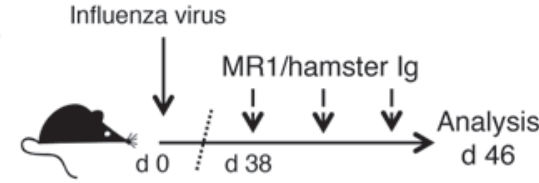

BLIMP-1-YFP

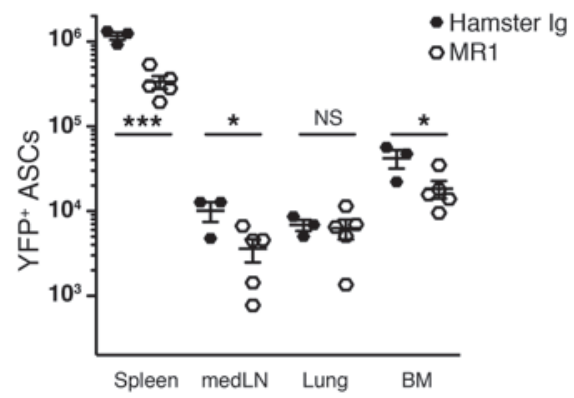

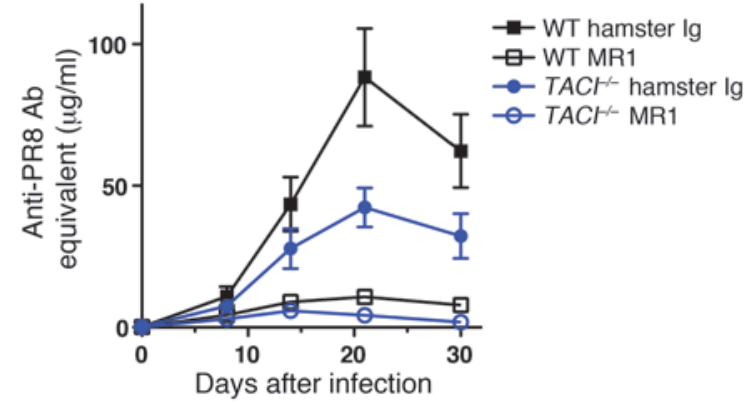

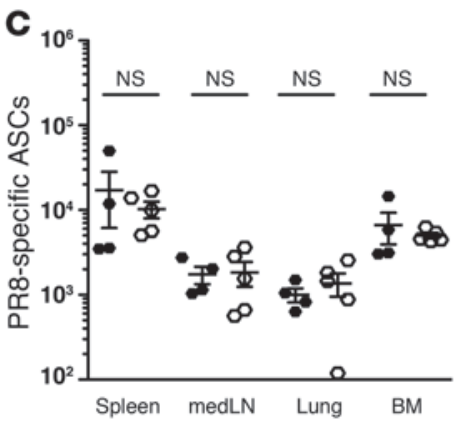

D

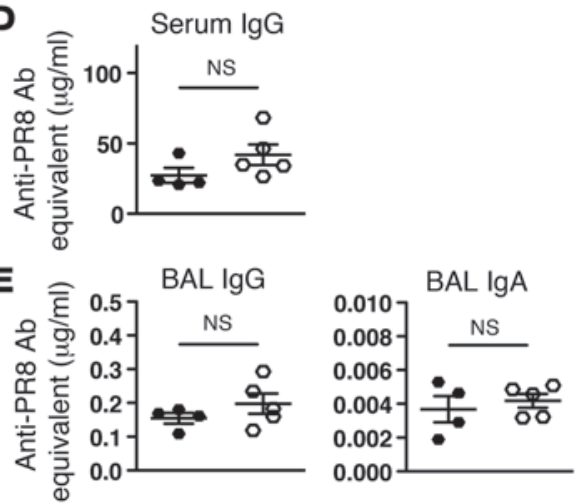

Figure 6

Induction but not maintenance of the antibody response to influenza is dependent on T cell help. (A) WT and $T A C l^{-/-}$mice $(n=7-8$ mice/group) were infected with influenza virus PR8. Starting on day 3 p.i., WT and $\mathrm{TACl}^{-/-}$mice received 5 i.p. injections of MR1 or hamster Ig control Ab (150 $\mu \mathrm{g} /$ mouse) in 3-day intervals. Blood samples were collected prior to (day 0) and days 8, 14, 21, 30, and 45 after infection and PR8-specific IgG $\mathrm{Ab}$ titers were determined by ELISA. (B-D) BLIMP-1-YFP mice were infected with influenza virus PR8 and treated 3 times in 3-day intervals starting on day 38 p.i. with MR1 or hamster lg Ab (150 $\mu \mathrm{g} / \mathrm{mouse})$. At day 46 p.i., spleen, medLN, lungs, and BM were harvested. Diagram in panel B applies to panels B-E. (B) YFP+ ASCs were enumerated by flow cytometry and (C) PR8-specific ASCs determined by ELISPOT. (D) $P R 8$-specific IgG Ab titers in serum and (E) IgG and IgA in BAL were measured by ELISA. All data with mean \pm SEM combine the results of 2 independent experiments. ${ }^{*} P<0.05,{ }^{* \star *} P<0.001$.

(Figure 6C). Likewise, antiviral serum IgG (Figure 6D) as well as virus-specific IgG and IgA in BAL (Figure 6E) were similar in MR1treated and control cohorts, suggesting that sustaining virus-specific ASCs and Ab production is independent of CD40L-mediated $\mathrm{T}$ cell help at this later time point.

$\mathrm{TACI}^{-1-}$ mice have reduced BLyS- and APRIL-expressing CD $11 b^{+}$cells in the RT. Studies using human myeloid cells indicated a role for TACI and its ligand BLyS in the activation and maturation of these cells $(39,62)$. To determine whether $\mathrm{CD} 11 \mathrm{~b}^{+}$cells are altered in $\mathrm{TACI}^{-/-}$mice following influenza virus infection, cells from lungs, BAL fluid, spleen, and medLN were stained for CD11b and CD11c and enumerated. Strikingly, at day 34 p.i., CD $11 b^{+} \mathrm{CD} 11 \mathrm{c}^{-}$cells, which accounted for a high percentage of innate cells in the lungs of WT mice, were significantly reduced in $\mathrm{TACI}^{-1-}$ mice as compared with WT mice (Figure 7, A and B). The percentage of $\mathrm{CD}_{11} \mathrm{~b}^{+} \mathrm{CD} 11 \mathrm{c}^{-}$cells was also significantly reduced in spleen and lungs of naive $\mathrm{TACI}^{-/-}$mice and early after infection (day 6 p.i.) (Supplemental Figure $8 \mathrm{~A}$ ). In contrast, $\mathrm{CD} 11 \mathrm{~b}^{+} \mathrm{CD} 11 \mathrm{c}^{+}$cells were present at similar frequencies in both mouse strains.

$\mathrm{CD} 11 \mathrm{~b}^{+} \mathrm{CD} 11 \mathrm{c}^{-}$cells include monocytes, macrophages, eosinophils, and basophils (Supplemental Figure 8B). To investigate which of the myeloid cells contribute to the production of BLyS and APRIL, we sorted cells from lungs of naive and infected mice (3-4 weeks p.i.) into subsets based on Abs to CD11c, CD11b, and Gr-1, which recognizes Ly6G and Ly6C (Figure 7C). BLyS and April expression was assessed by real-time PCR. Gr- $1^{+}$neutrophils expressed BLyS but not April. Gr-1 ${ }^{\text {lo }}$ cells expressed both BLyS and April mRNA (Figure 7D). In contrast, $\mathrm{CD} 11 \mathrm{~b}^{+} \mathrm{CD} 11 \mathrm{c}^{+}$cells predominantly expressed April, but not BLyS, and CD11b ${ }^{-}$CD $11 c^{-}$ cells showed insignificant levels of both cytokines. Interestingly, although the frequency of $\mathrm{CD} 11 \mathrm{~b}^{+} \mathrm{CD} 11 \mathrm{c}^{-}$cells was significantly reduced in $\mathrm{TACI}^{---}$mice as compared with WT mice, there was no preferential reduction in individual Ly6C- and Ly6G-expressing cell subsets (Supplemental Figure 8, C and D).

IL-6 plays an important role in humoral immunity to influenza virus infection and can be produced by myeloid cells and DCs $(35,63)$. To test whether the reduction of myeloid cells in $\mathrm{TACI}^{-1-}$ mice has an impact on IL-6 production, we measured Il6 expression by real-time PCR on whole mouse lung homogenates from $\mathrm{WT}$ and $\mathrm{TACI}^{-1-}$ mice at various times after infection. Il6 was similarly induced on day 6 p.i.; however, by day 15 p.i. TACI $^{-1-}$ mice had reduced expression of Il6 as compared with WT mice. Il6 was 


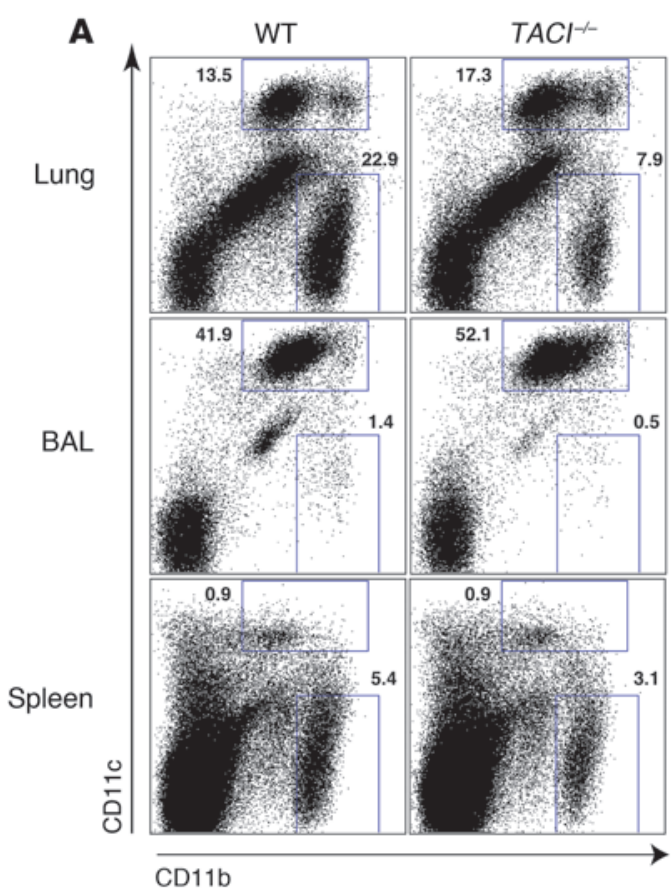

B
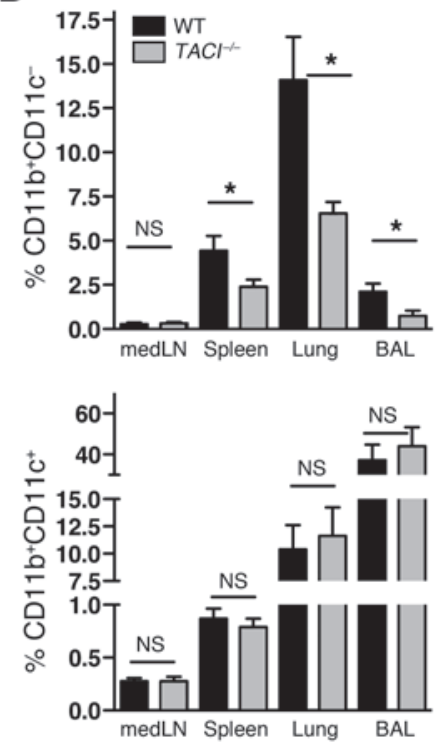

\section{Figure 7}

Reduction of BLyS- and APRIL-expressing $\mathrm{CD} 11 \mathrm{~b}^{+} \mathrm{CD} 11 \mathrm{c}^{-}$cells in lungs of $\mathrm{TACl}^{-/-}$ mice after influenza virus infection. (A) Flow cytometry plots with percentages of CD11 $b^{+}$CD 11 $c^{+}$and CD11 ${ }^{+}$CD 11 $c^{-}$cells in lungs, BAL, and spleen isolated from WT or $\mathrm{TACl}^{-/-}$mice at day 34 p.i. (B) Frequency of CD11b+CD11c ${ }^{-}$and CD11b+CD11 $\mathrm{c}^{+}$ cells in various organs of WT and $\mathrm{TACl}^{-/-}$ mice at day 34 p.i. Data with mean \pm SEM combine the results of 3 independent experiments ( $n=8$ mice/group). (C) Identification of cell subsets in lungs of mice based on expression of CD11b, CD11c, and Gr-1 used for purification by FACS. DN, double negative (CD11b-CD11c-). (D) Real-time PCR analysis of BLyS and April mRNA expression in cell subsets sorted from lungs as shown in $\mathbf{C}$ of naive mice (solid bars) and mice 3-4 weeks p.i. Data with mean \pm SEM are from 2 independent experiments. ${ }^{*} P<0.05$.
C

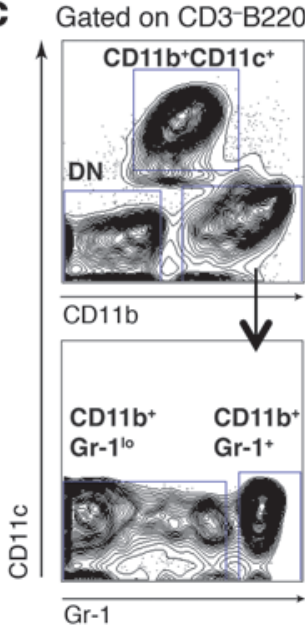

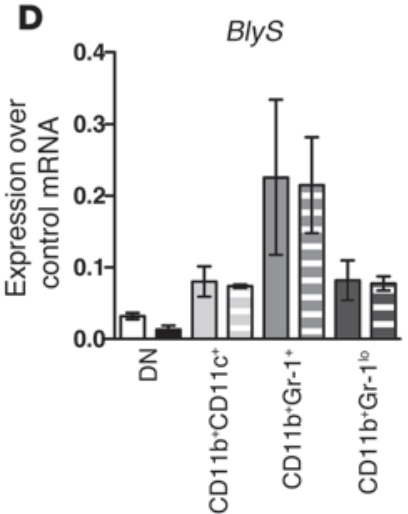

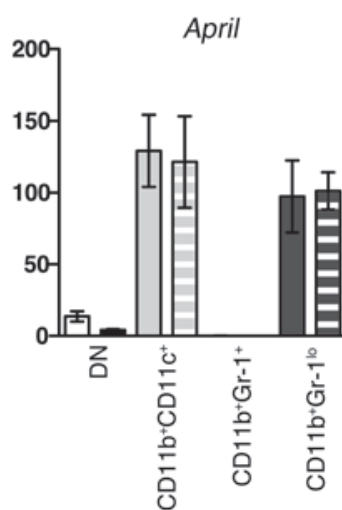

undetectable in both mouse strains by day 20 p.i. and thereafter (Supplemental Figure 8E).

To investigate whether the reduction in $\mathrm{CD} 11 \mathrm{~b}^{+} \mathrm{CD} 11 \mathrm{c}^{-}$cells was due to a cell-intrinsic function of TACI, we generated mixed $\mathrm{BM}$ chimeras by reconstituting irradiated congenic CD 45.1 hosts with a 1:1 mixture of BM cells from CD45.1 WT and CD45.2 $\mathrm{TACI}^{-/-}$mice (Supplemental Figure 9). When mice were bled 6 weeks after reconstitution to determine the ratio of $\mathrm{CD} 45.1^{+}$to CD $45.2^{+}$cells, WT BM donors represented $61.6 \% \pm 2.64 \%$ of cells in the blood of recipient mice. For subsequent analysis, the ratio of WT to $\mathrm{TACI}^{-/-}$was set to equal 1 . Next, BM chimeras were infected with influenza virus and analyzed 31 days later for the ratio of WT to $\mathrm{TACI}^{-/}$- donor cells among $\mathrm{CD} 138^{+} \mathrm{ASC}$ and $\mathrm{CD} 11 \mathrm{~b}^{+} \mathrm{CD} 11 \mathrm{c}$ cells (Supplemental Figure 9, B and C). CD138 ${ }^{+}$ASCs in all organs analyzed showed a significant overrepresentation of WT-derived donor cells, suggesting that ASCs from $\mathrm{TACI}^{-/-}$mice have an intrinsic disadvantage compared with ASCs that express TACI. In contrast, no bias for cells derived from WT or $\mathrm{TACI}^{-/-}$mice was observed within the CD11 $\mathrm{b}^{+} \mathrm{CD} 11 \mathrm{c}^{-}$cell population. These data imply that the reduction in $\mathrm{CD} 11 \mathrm{~b}^{+} \mathrm{CD} 11 \mathrm{c}^{-}$cells in $\mathrm{TACI}^{-/-}$mice compared with WT mice (Figure 7, A and B, and Supplemental Figure $8 \mathrm{~A}$ ) is due to cell-extrinsic regulatory mechanisms.

$\mathrm{TACI}^{-/-}$mice exhibit reduced Ab-mediated protection. Because Abs are important for viral neutralization (1), we determined whether the reduced antiviral $\mathrm{Ab}$ titers in $\mathrm{TACI}^{-/}$- mice (Figure $4 \mathrm{~A}$ ) resulted in a lack of virus-neutralizing capacity and decreased protection against viral challenge. Serum was collected from WT and $\mathrm{TACI}^{-/-}$ mice 2 months after infection and tested for the ability to prevent $\mathrm{rbchemagglutination} \mathrm{by} \mathrm{virus} \mathrm{using} \mathrm{an} \mathrm{in} \mathrm{vitro} \mathrm{hemagglutination}$ inhibition (HI) assay (64). The HI capacity of sera from $T A C I^{-/-}$ mice was reduced (Figure 8A). To examine whether lower Ab titers in $\mathrm{TACI}^{-/-}$mice could alter the ability to neutralize antigenic variant influenza viruses, we extended our studies to a different H1N1 isolate, influenza $\mathrm{A} / \mathrm{SW} / 31$ (SW) virus. Abs induced with PR8 


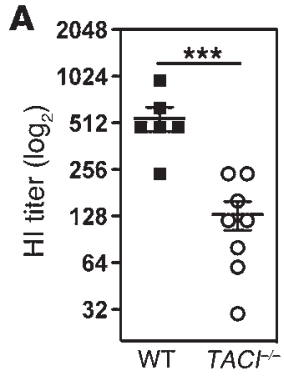

B

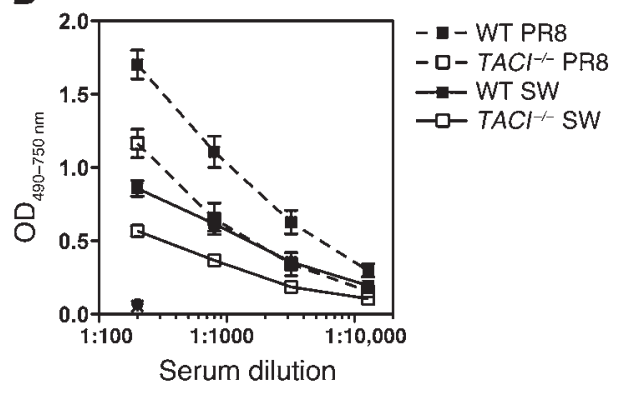

C

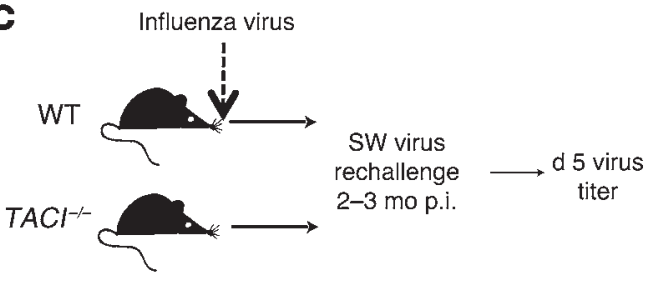

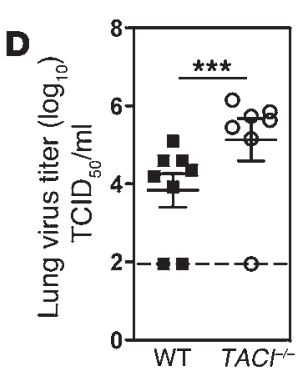

\section{Figure 8}

$\mathrm{TACl}^{-/-}$mice have reduced Ab-mediated protection. (A) $\mathrm{HI}$ assay with sera from WT and $\mathrm{TACl}^{-/-}$mice collected 3 months after infection with influenza virus PR8. (B) Sera from WT and $\mathrm{TACl}^{--}$mice ( $n=8-9$ mice/group) 2-3 months after infection were tested for binding to PR8 (dashed line) and SW (solid line) virus by ELISA. As a control, sera from naive mice are shown at a dilution of 1:200. (C) Two to 3 months after primary infection with influenza virus PR8, WT and $\mathrm{TACl}^{-/-}$mice were challenged with 2,000 $\mathrm{TCID}_{50} / 30 \mu \mathrm{l}$ of SW virus, and lungs were assayed for viral titers 5 days later. (D) Viral titers in lungs from PR8-infected WT and $\mathrm{TACl}^{-/-}$ mice 5 days after challenge with SW virus. Dotted line represents limit of detection for this assay. Data with mean \pm SEM summarize 2 independent experiments. ${ }^{* \star *} P<0.001$. infection exhibited poor cross-reactivity to SW virus (Figure $8 \mathrm{~B}$ ). Moreover, Abs in sera from PR8-infected $\mathrm{TACI}^{-/-}$mice bound SW virus less efficiently than Abs in sera from WT mice. To test protection in vivo, we challenged WT and $\mathrm{TACI}^{-/-}$mice with SW virus 2-3 months after primary infection with PR8 virus (Figure $8 \mathrm{C}$ ). $\mathrm{TACI}^{-/-}$mice displayed 10-fold higher viral titers in the lungs as compared with WT mice 5 days after challenge (Figure 8D). Thus, protection against a secondary infection with an antigenic variant influenza virus is significantly impaired in the absence of TACI.

\section{Discussion}

Here we identify a critical role for TACI and its ligands BLyS and APRIL in the maintenance of protective antiviral ASCs. Following infection with influenza, ASCs increase at various anatomical sites, including the RT, where they are sustained at elevated numbers for several months (Figure 1C and Figure 2C). The majority of lung ASCs exhibit low cell cycle activity, suggesting that they are long-lived (Supplemental Figure 2C). However, unlike long-lived ASCs resident in the spleen and BM, ASCs in the lungs of influenza-infected mice are susceptible to the effects of whole-body irradiation (Figure 2, B and C), which points toward a cell-extrinsic mechanism for ASC survival.

We demonstrate that neutralization of BLyS and APRIL, but not BLyS alone, 5 weeks after infection results in substantially decreased virus-specific ASCs in BM and lungs, correlating with reduced $\mathrm{Ab}$ titers in serum and BAL (Figure 3 and Supplemental Figure 3). Interestingly, Aprit ${ }^{-/}$mice or April-transgenic mice showed normal early antiviral ASC and Ab responses (65); however, the persistence of ASCs was not investigated in these studies. Here we demonstrate that the early antiviral $\mathrm{Ab}$ and ASC response (day 8 p.i.) was similar in WT and $\mathrm{TACI}^{-/-}$mice (Figure 4, A and B, and Figure 5A), but by 3-4 weeks p.i. TACI-deficient mice exhibited significantly lower antiviral $\mathrm{Ab}$ titers in serum and BAL correlating with reduced numbers of virus-specific ASCs (Figure 4, A and B, and Figure $5 \mathrm{~B}$ ). In contrast to $\mathrm{TACI}^{-/-}$mice, there was no difference in the humoral response to influenza virus in $B C M A^{-/-}$mice (Supplemental Figure 7). Although BCMA has been implicated in survival of BM ASCs (25), our data and those of others (66) suggest that BCMA does not play a major role in mediating survival of virally induced ASCs.

In vitro studies have indicated that signals through TACI can play an important role in the induction of class switch recombination $(41-43,48)$. Interestingly, our data suggest that the initial induction of isotype switching after influenza virus infection is largely TACI independent in vivo: The number of virus-specific IgG- and IgA-producing cells in medLN of WT and $\mathrm{TACI}^{-/-}$mice was similar at 6-8 days p.i. (Figure 5A). We cannot exclude the possibility that TACI functions in ASC class switching at later times, particularly in the lung, when costimulatory signals and help from effector T cells may have become sparse. However, we demonstrate that blockade of CD40L 5 weeks p.i. does not impact antiviral ASCs and Ab production locally in the lungs (Figure 6, B-D).

In humans, individuals carrying mutations in the TNFRSF13B gene encoding TACI are prone to developing CVID, characterized by low serum IgG and IgA concentrations and recurrent bacterial infections $(67,68)$. TACI mutations also result in severely decreased proportions of isotype-switched B cells, suggesting defects in the generation and/or maintenance of memory B cells in the absence of functional TACI $(68,69)$. TACI mutations can interfere with class switch recombination in humans, potentially through a failure to properly induce activation-induced deaminase $(A I D)$ expression $(43,67,68)$. In addition, naive B cells from TACImutated individuals fail to secrete IgA Abs after stimulation in vitro with BLyS or APRIL, suggesting an important role for TACI in human mucosal immunity (67). In line with this observation, CVID patients often experience pneumonia, potentially leading to chronic lung disease (70). Moreover, defects in the expression of TACI, which we showed in the present study to be important for the survival of long-lived ASCs in the BM, may also account for the decreased serum IgG and IgA concentrations observed in patients with TACI mutations (67-69).

Strikingly, we show a site-specific requirement for TACI in the antiviral ASC response. Lung and BM ASCs, but not ASCs in medLN and spleen, were significantly reduced after treatment 
with TACI-Fc or in $\mathrm{TACI}^{-/-}$mice 5 weeks p.i. (Figure 3, B and C, and Figure $5 \mathrm{~B}$ ). Our findings raise the question as to what could account for the difference in TACI-dependent survival of virusspecific ASCs at these sites. Organ-specific access to TLR ligands, for example at mucosal sites, could positively regulate BLyS and/ or APRIL expression $(26,30,71)$ and thus influence local isotype switching and/or ASC survival. Studies with human B cells have suggested that mucosal IgG and IgA responses to poly(I:C), a surrogate for viral dsRNA and a ligand for TLR3, can be potentiated with BLyS $(27,28)$. In addition to the more ubiquitously present myeloid cell types, specialized cell subsets in the RT such as airway epithelial cells and alveolar macrophages could allow for local regulation of APRIL and BlyS production (26-28, 33, 34, 71, 72). Geurtsvankessel at al. recently demonstrated that local depletion of CD $11 \mathrm{c}^{+}$DCs in the lungs of influenza-infected mice coincided with decreased IgA titers in airway secretions and ASCs in the lung (73). This treatment could have removed a source of cells that are able to produce ASC survival factors. Indeed, we show in this study that $\mathrm{CD} 11 \mathrm{~b}^{+} \mathrm{CD} 11 \mathrm{c}^{+}$cells (including DCs and alveolar macrophages) isolated from lungs exhibited high levels of April mRNA (Figure 7D). Moreover, we demonstrate that CD11b+CD11 $\mathrm{c}^{-}$cells included subsets with increased BLyS and APRIL expression as compared with cells that were CD $11 \mathrm{~b}^{-} \mathrm{CD} 11 \mathrm{c}^{-}$. Importantly, we show that these $\mathrm{CD} 11 \mathrm{~b}^{+} \mathrm{CD} 11 \mathrm{c}^{-}$cells were reduced in $\mathrm{TACI}^{-/-}$mice (Figure 7, A and B, Supplemental Figure 8A), suggesting a model in which TACI signaling in innate cell subsets indirectly regulates ASC differentiation and survival. Of note, whole body irradiation used in this study to determine the lifespan of ASCs may have ablated these cells, thus indirectly affecting ASC survival in the RT (Figure 2, B and C). Moreover, it has been demonstrated that TACI may be involved in human monocyte maturation and differentiation $(39,62)$. A reduction in macrophages was also observed in APRIL-deficient mice infected with influenza virus (65). Our results support the possibility, therefore, that the predisposition to lung infections in TACI-deficient individuals is mediated through a failure to maintain isotype-switched ASCs in the lungs

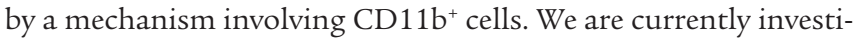

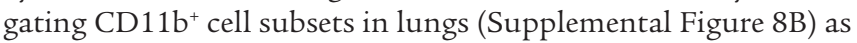
well as lymphoid organs during influenza infection, with particular attention to eosinophils (74) and basophils (75), which have been implicated in controlling ASC survival.

Finally, we demonstrate that reduction of virus-specific ASCs in the lungs and BM correlates with significantly lower virus-specific $\mathrm{Ab}$ titers in the airways and serum. The importance of antiviral Abs for protection against reinfection is well documented $(1,76)$. There are several mechanisms for antiviral Abs to control influenza infection; the most efficient is through viral neutralization mediated predominantly by Abs against hemagglutinin (77). We show that decreased serum Ab-titers in $\mathrm{TACI}^{-/-}$mice translated into a significant reduction in $\mathrm{HI}$ (Figure 8A) and less efficient cross-reactive binding of serum Abs to another H1N1 virus (Figure 8B). Importantly, this abrogates the protection of mice against secondary viral infection with an antigenic variant virus (Figure 8D), such as those that arise during antigenic drift of influenza strains.

Taken together, our observations reveal a critical role for TACI in generating optimal humoral immunity and maintaining protection against secondary viral infection. Targeting TACI on both $B$ cells and innate cells for enhanced antiviral ASC survival could lead to improved $\mathrm{Ab}$ titer maintenance and protection and may inform future vaccine strategies.

\section{Methods}

Supplemental Methods are available online with this article; doi:10.1172/ JCI57362DS1.

Mice. BLIMP-1-YFP (53) and TACI ${ }^{-/-}$mice (46) on a C57BL/6 background were housed and bred at the Wistar Institute under specific pathogen-free conditions. C57BL/6 WT and congenic CD45.1 (Ly5.2/Cr) mice were purchased from the National Cancer Institute. Male and female mice used in studies were 8-12 weeks old, and all experiments were performed under a protocol approved by the Wistar Institute Animal Care and Use Committee.

Influenza viruses and infection. Influenza viruses were grown in the allantoic fluid of 10-day embryonated chicken eggs (B\&E Eggs) and stored at $-80^{\circ} \mathrm{C}$. Mice were immobilized with ketamine/xylazine $(70 \mathrm{mg} / 10 \mathrm{mg} / \mathrm{kg})$ and infected intranasally with a dose of $500 \mathrm{TCID}_{50} / 30 \mu \mathrm{l}$ mouse-adapted PR8 virus (influenza virus A/Puerto Rico/8/34; H1N1; Mount Sinai strain) as described previously (78). SW virus (influenza virus A/Swine/31; H1N1) for rechallenge was given at a dose of $2,000 \mathrm{TCID}_{50} / 30 \mu \mathrm{l}$.

Cell preparations. Tissues were collected and cells prepared as described previously (78). In brief, blood was collected through cardiac puncture. BAL was harvested by flushing the airway compartment with $0.8 \mathrm{ml}$ PBS with $1 \%$ FBS (PBS/FBS) 3 times. Perfused lungs were digested in HBSS with $400 \mathrm{U} / \mathrm{ml}$ Collagenase $\mathrm{D}$ (Roche) for 30 minutes at $37^{\circ} \mathrm{C}$. Tissues were passed through metal wire mesh, and after rbc lysis, cells were resuspended in Iscove's complete medium containing 10\% FBS for ELISPOT assays or in PBS/FBS for flow cytometric analysis.

Flow cytometry. For surface staining, cells were incubated first with Fcblock (anti-CD32/anti-CD16), then with various Abs. The following antibodies were purchased from eBioscience if not indicated otherwise: CD3E-FITC, CD4-PerCPcy5.5, CD8-PerCPcy5.5, CD11b-PerCPcy5.5, CD19-PEcy7, IgD-eFluor450, Fas-PE, PNA-FITC (Sigma-Aldrich), CD45R/ B220-FITC (BioLegend), Gr-1-PE, CD138-PE and -APC, and CD11c-APC (BD). Analysis was performed on a FACSCalibur or LSR II (BD). Data were processed using FlowJo software (Tree Star).

Histology. Tissues were fixed in $4 \%$ formaldehyde (Ricca Chemical) with $10 \%$ sucrose (Fluka) for 6-8 hours to preserve YFP expression and frozen in OCT medium (Tissue-Tek). Sections from organs of BLIMP-1-YFP mice were stained with B220-PE or CD4-PE (BD). All histology was examined and recorded on an upright Nikon E600 Microscope with the image software Image-Pro (Media Cybernetics).

Irradiation of influenza-virus-infected mice. Influenza virus-infected BLIMP-1YFP mice received whole-body irradiation (7.5 Gy, cesium source) at indicated times after infection. Within 24 hours, mice were injected intravenously with $1 \times 10^{6} \mathrm{~T}$ cell-depleted BM cells from congenic CD45.1 mice.

Neutralization of BLyS and APRIL and blockade of CD40L in vivo. To neutralize BLyS and APRIL, we injected BLIMP-1-YFP mice i.p. with $100 \mu \mathrm{g}$ TACI-FC or human IgG control Ab starting at day 35 p.i. every 2-3 days for 2 weeks.

To block CD40L, we injected mice i.p. with $150 \mu \mathrm{g}$ MR1 or hamster IgG control Ab (BioXCell) every 3 days between days 3 and 15 p.i. or 3 times starting on day 38 p.i.

ELISA and ELISPOT assay. Antiviral Ab concentrations in serum and BAL were determined by ELISA as described previously (79). To determine virusspecific or total IgG and IgA, we coated plates with purified virus or antimouse $\operatorname{Ig}_{(\mathrm{H}+\mathrm{L})}$ and anti-mouse IgA (R5-140). Concentrations of Abs were calculated based on purified anti-HA Ab standards of IgG (H36-4-5.2), IgA (H37-66-7), or IgM (H35-C7-2R1) isotypes and graphed as Ab equivalents.

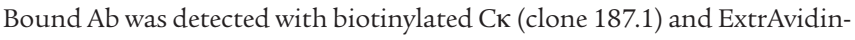
coupled alkaline phosphatase (AP) (Sigma-Aldrich), or anti-IgG, IgM, and IgA conjugated to AP (Sigma-Aldrich) and developed with $p$-nitrophenyl phosphate (pNPP) (Sigma-Aldrich). The optical intensity $\left(\mathrm{OD}_{405-750 \mathrm{~nm}}\right)$ was determined with an ELISA reader (Molecular Devices) and calculated using SoftMax Pro software (Molecular Devices). 
To detect PR8-specific ASCs, we coated ELISPOT plates (Millipore) with 100 hemagglutination units (HAU) purified PR8 per well in $100 \mu \mathrm{l}$ PBS the day before and kept them at $4^{\circ} \mathrm{C}$. Plates were washed and blocked with Iscove's medium containing 10\% FBS (Atlanta Biologicals) prior to plating of cells. Cell suspensions in various dilutions were plated and incubated for $6-7$ hours at $37^{\circ} \mathrm{C}$ in humidified air $/ 7 \% \mathrm{CO}_{2}$. Ab spots were detected with anti-IgM, anti-IgG, and anti-IgA conjugated to AP (SigmaAldrich) and developed with NBT/BCIP substrate (Sigma-Aldrich). Automated spot counts were performed with an ImmunoSpot Reader (CTL) and ImmunoSpot satellite software (CTL). Unless stated otherwise, PR8-specific ASCs represent a combination of virus-specific IgM-, IgG-, and IgA-secreting cells.

Real-time PCR. Cell populations from lungs were sorted based on CD11b, CD11c, and Gr-1 RNA, extracted with the RNeasy Kit according to the manufacturer's instructions (QIAGEN) and reverse transcribed by Superscript II Reverse Transcriptase (Invitrogen). Real-time PCR was performed as previously described (36). Master Mix and primer and probe sets for mouse Gapdh, Il6, BLyS, and April were from Applied Biosystems. The ABI 7300 system (Applied Biosystems) was used for real-time PCR, and the cycling threshold method $\left(2^{-(\Delta \Delta \mathrm{Ct})}\right)$ was used for relative quantification of the gene of interest to Gapdh (80). In some experiments, expression levels were normalized based on control RNA (Zyagen).

HI assay. The HI assay was performed as described previously (64). Serum or BAL samples were serially diluted and mixed in equal volumes with purified PR8 virus. After 1 hour, chicken rbc (B\&E Eggs) were added, and the pattern of agglutination was recorded. The HI titer is expressed as reciprocal of the highest serum dilution at which virus was inhibited from agglutinating rbc.

Determination of infectious virus titers in lungs. The concentration of infectious virus in lungs was determined by titration of homogenized tissues in
Madin-Darby canine kidney cell (MDCK) microcultures as described previously (81). Lung titers are expressed as dilution of lung extract at which $50 \%$ of the MDCK cultures revealed virus growth $\left(\operatorname{TCID}_{50} / \mathrm{ml}\right)$.

Statistics. Data are presented as mean \pm SEM. Statistical significance between 2 groups was calculated using an unpaired 2-tailed Student's $t$ test. Multiple groups were compared using a 1-way ANOVA. All statistical tests were performed using Prism software (GraphPad Software).

\section{Acknowledgments}

The authors wish to thank S. Hensley, D. Simons, J. Scholz, A. Bortnick, and W. Loo for helpful discussion and comments on the manuscript; E.J. Wherry for providing the influenza tetramer; J. Faust, D. Hussey, and D. Ambrose in the Wistar flow cytometry facility for assistance in cell sorting and J. Hayden and F. Keeney in the Wistar microscopy facility for their help. This work is supported by the Wistar Cancer Center Core Grant P30 CA10815, NIH grant U19 AI083022, and a grant from the Commonwealth of Pennsylvania to J. Erikson and A.J. Caton; NIH grant R01 AI054488 to M.P. Cancro; AI061093 and AI071087 to E. Meffre; AI52861 and AG58066 to D. Allman; a grant from the Lupus Research Institute to L.D. Erickson; and T32 Training grants CA09171-32 to A.I. Wolf and AI055428 to W.J. Quinn III.

Received for publication January 31, 2011, and accepted in revised form July 25, 2011.

Address correspondence to: Jan Erikson, 3601 Spruce Street, The Wistar Institute, Philadelphia, Pennsylvania 19104, USA. Phone: 215.898.3823; Fax: 215.573.9053; E-mail: jan@wistar.org.
1. Gerhard W. The role of the antibody response in influenza virus infection. Curr Top Microbiol Immunol. 2001;260:171-190.

2. Slifka MK, Antia R, Whitmire JK, Ahmed R. Humoral immunity due to long-lived plasma cells. Immunity. 1998;8(3):363-372.

3. Amanna IJ, Carlson NE, Slifka MK. Duration of humoral immunity to common viral and vaccine antigens. N Engl J Med. 2007;357(19):1903-1915.

4. Dörner T, Radbruch A. Antibodies and B cell memory in viral immunity. Immunity. 2007;27(3):384-392.

5. Jones PD, Ada GL. Influenza virus-specific antibodysecreting cells in the murine lung during primary influenza virus infection. JVirol. 1986;60(2):614-619.

6. Joo HM, He Y, Sangster MY. Broad dispersion and lung localization of virus-specific memory B cells induced by influenza pneumonia. Proc Natl Acad Sci US A. 2008;105(9):3485-3490.

7. Owens SL, Osebold JW, Zee YC. Dynamics of B-lymphocytes in the lungs of mice exposed to aerosolized influenza virus. Infect Immun. 1981;33(1):231-238.

8. Hyland L, Sangster M, Sealy R, Coleclough C. Respiratory virus infection of mice provokes a permanent humoral immune response. J Virol. 1994; 68(9):6083-6086.

9. Jones PD, Ada GL. Persistence of influenza virusspecific antibody-secreting cells and B-cell memory after primary murine influenza virus infection. Cell Immunol. 1987;109(1):53-64.

10. Calame K. Transcription factors that regulate memory in humoral responses. Immunol Rev. 2006; 211:269-279.

11. Kallies A, et al. Plasma cell ontogeny defined by quantitative changes in blimp-1 expression. J Exp Med. 2004;200(8):967-977.

12. Shapiro-Shelef M, Lin K-I, Savitsky D, Liao J, Calame K. Blimp-1 is required for maintenance of long-lived plasma cells in the bone marrow. J Exp Med. 2005;202(11):1471-1476.
13. Manz RA, Thiel A, Radbruch A. Lifetime of plasma cells in the bone marrow. Nature. 1997; 388(6638):133-134.

14. O'Connor BP, Cascalho M, Noelle RJ. Short-lived and long-lived bone marrow plasma cells are derived from a novel precursor population. J Exp Med. 2002;195(6):737-745.

15. Slifka MK, Matloubian M, Ahmed R. Bone marrow is a major site of long-term antibody production after acute viral infection. J Virol. 1995;69(3):1895-1902.

16. Manz RA, Lohning M, Cassese G, Thiel A, Radbruch A. Survival of long-lived plasma cells is independent of antigen. Int Immunol. 1998;10(11):1703-1711.

17. Tarlinton D, Radbruch A, Hiepe F, Dorner T. Plasma cell differentiation and survival. Curr Opin Immunol. 2008;20(2):162-169.

18. Cassese G, et al. Plasma cell survival is mediated by synergistic effects of cytokines and adhesion-dependent signals. J Immunol. 2003;171(4):1684-1690.

19. Xiang Z, et al. FcgammaRIIb controls bone marrow plasma cell persistence and apoptosis. Nat Immunol. 2007;8(4):419-429.

20. Hargreaves DC, et al. A coordinated change in chemokine responsiveness guides plasma cell movements. J Exp Med. 2001;194(1):45-56.

21. Kunkel EJ, Butcher EC. Plasma-cell homing. Nat Rev Immunol. 2003;3(10):822-829.

22. Mackay F, Schneider P, Rennert P, Browning J. BAFF AND APRIL: a tutorial on B cell survival. Annu Rev Immunol. 2003;21:231-264.

23. Cancro MP. The BLyS family of ligands and receptors: an archetype for niche-specific homeostatic regulation. Immunol Rev. 2004;202:237-249.

24. Benson MJ, et al. Cutting edge: the dependence of plasma cells and independence of memory B cells on BAFF and APRIL. J Immunol. 2008; 180(6):3655-3659.

25. O'Connor BP. BCMA is essential for the survival of long-lived bone marrow plasma cells. J Exp Med.
2003;199(1):91-98

26. Huard B, et al. APRIL secreted by neutrophils binds to heparan sulfate proteoglycans to create plasma cell niches in human mucosa. J Clin Invest. 2008;118(8):2887-2895.

27. Kato A, Truong-Tran AQ, Scott AL, Matsumoto K, Schleimer RP. Airway epithelial cells produce B cell-activating factor of TNF family by an IFNbeta-dependent mechanism. J Immunol. 2006; 177(10):7164-7172.

28. Xu W, et al. Viral double-stranded RNA triggers Ig class switching by activating upper respiratory mucosa B cells through an innate TLR3 pathway involving BAFF. J Immunol. 2008;181(1):276-287.

29. Katsenelson N, Kanswal S, Puig M, Mostowski H, Verthelyi D, Akkoyunlu M. Synthetic CPG oligodeoxynucleotides augment BAFF- and APRIL-mediated immunoglobulin secretion. Eur J Immunol. 2007; 37(7):1785-1795.

30. Tezuka H, et al. Regulation of IgA production by naturally occurring TNF/iNOS-producing dendritic cells. Nature. 2007;448(7156):929-933.

31. Balázs M, Martin F, Zhou T, Kearney J. Blood dendritic cells interact with splenic marginal zone B cells to initiate $\mathrm{T}$-independent immune responses. Immunity. 2002;17(3):341-352.

32. MacLennan I, Vinuesa C. Dendritic cells, BAFF, and APRIL: innate players in adaptive antibody responses. Immunity. 2002;17(3):235-238.

33. Litinskiy MB, et al. DCs induce CD40-independent immunoglobulin class switching through BLyS and APRIL. Nat Immunol. 2002;3(9):822-829.

34. Bessa J, et al. Alveolar macrophages and lung dendritic cells sense RNA and drive mucosal IgA responses. J Immunol. 2009;183(6):3788-3799.

35. Mohr E, et al. Dendritic cells and monocyte/macrophages that create the IL-6/APRIL-rich lymph node microenvironments where plasmablasts mature. JImmunol. 2009;182(4):2113-2123. 
36. Stadanlick JE, et al. Tonic B cell antigen receptor signals supply an NF-kappaB substrate for prosurvival BLyS signaling. Nat Immunol. 2008;9(12):1379-1387.

37. Ng LG, et al. BAFF costimulation of Toll-like receptor-activated B-1 cells. Eur J Immunol. 2006; 36(7):1837-1846.

38. Treml LS, Crowley JE, Cancro MP. BLyS receptor signatures resolve homeostatically independent compartments among naïve and antigen-experienced B cells. Semin Immunol. 2006;18(5):297-304.

39. Chang SK, Arendt BK, Darce JR, Wu X, Jelinek DF. A role for BLyS in the activation of innate immune cells. Blood. 2006;108(8):2687-2694.

40. Mackay F, Leung H. The role of the BAFF/APRIL system on T cell function. Semin Immunol. 2006; 18(5):284-289.

41. Castigli E, Wilson SA, Elkhal A, Ozcan E, Garibyan L, Geha RS. Transmembrane activator and calcium modulator and cyclophilin ligand interactor enhances CD40-driven plasma cell differentiation. J Allergy Clin Immunol. 2007;120(4):885-891.

42. Castigli E, et al. TACI and BAFF-R mediate isotype switching in B cells. J Exp Med. 2005;201(1):35-39.

43. He B, et al. The transmembrane activator TACI triggers immunoglobulin class switching by activating B cells through the adaptor MyD88. Nat Immunol. 2010;11(9):836-845.

44. Sakurai D, Kanno Y, Hase H, Kojima H, Okumura $\mathrm{K}$, Kobata T. TACI attenuates antibody production costimulated by BAFF-R and CD40. Eur I Immunol. 2007;37(1):110-118.

45. Yan $M$, et al. Activation and accumulation of B cells in TACI-deficient mice. Nat Immunol. 2001; 2(7):638-643.

46. von Bülow GU, van Deursen JM, Bram RJ. Regulation of the T-independent humoral response by TACI. Immunity. 2001;14(5):573-582.

47. Mantchev GT, Cortesão CS, Rebrovich M, Cascalho $\mathrm{M}$, Bram RJ. TACI is required for efficient plasma cell differentiation in response to T-independent type 2 antigens. J Immunol. 2007;179(4):2282-2288.

48. Ozcan E, Garibyan L, Lee JJ-Y, Bram RJ, Lam K-P, Geha RS. Transmembrane activator, calcium modulator, and cyclophilin ligand interactor drives plasma cell differentiation in LPS-activated B cells. J Allergy Clin Immunol. 2009;123(6):1277-1286.e1275.

49. Yan M, Marsters SA, Grewal IS, Wang H, Ashkenazi A, Dixit VM. Identification of a receptor for BLyS demonstrates a crucial role in humoral immunity. Nat Immunol. 2000;1(1):37-41.

50. Yu G, et al. APRIL and TALL-I and receptors BCMA and TACI: system for regulating humoral immunity. Nat Immunol. 2000;1(3):252-256

51. Xia XZ, et al. TACI is a TRAF-interacting receptor for TALL-1, a tumor necrosis factor family member involved in B cell regulation. J Exp Med. 2000; 192(1):137-143.
52. Ingold $\mathrm{K}$, et al. Identification of proteoglycans as the APRIL-specific binding partners. J Exp Med. 2005;201(9):1375-1383

53. Rutishauser RL, et al. Transcriptional repressor Blimp-1 promotes CD8(+) T cell terminal differentiation and represses the acquisition of central memory T cell properties. Immunity. 2009;31(2):296-308.

54. Moyron-Quiroz JE, et al. Role of inducible bronchus associated lymphoid tissue (iBALT) in respiratory immunity. Nat Med. 2004;10(9):927-934.

55. Gross JA, et al. TACI and BCMA are receptors for a TNF homologue implicated in B-cell autoimmune disease. Nature. 2000;404(6781):995-999.

56. Scholz JL, et al. BLyS inhibition eliminates primary $B$ cells but leaves natural and acquired humoral immunity intact. Proc Natl Acad Sci U S A. 2008; 105(40):15517-15522.

57. Castigli E, et al. Impaired IgA class switching in APRIL-deficient mice. Proc Natl Acad Sci U S A. 2004; 101(11):3903-3908.

58. Coro ES, Chang WLW, Baumgarth N. Type I IFN receptor signals directly stimulate local B cells early following influenza virus infection. J Immunol. 2006; 176(7):4343-4351.

59. Sealy R, Surman S, Hurwitz JL, Coleclough C. Antibody response to influenza infection of mice: different patterns for glycoprotein and nucleocapsid antigens. Immunology. 2003;108(4):431-439.

60. Diaz-de-Durana Y, Mantchev GT, Bram RJ, Franco A. TACI-BLyS signaling via B-cell-dendritic cell cooperation is required for naive $\mathrm{CD} 8+\mathrm{T}$-cell priming in vivo. Blood. 2006;107(2):594-601.

61. Lee BO, et al. CD4 T cell-independent antibody response promotes resolution of primary influenza infection and helps to prevent reinfection. J Immunol. 2005;175(9):5827-5838.

62. Chang SK, Mihalcik SA, Jelinek DF. B lymphocyte stimulator regulates adaptive immune responses by directly promoting dendritic cell maturation. JImmunol. 2008;180(11):7394-7403.

63. Dienz $\mathrm{O}$, et al. The induction of antibody production by IL- 6 is indirectly mediated by IL- 21 produced by CD4+ T cells. J Exp Med. 2009;206(1):69-78.

64. Scherle PA, Palladino G, Gerhard W. Mice can recover from pulmonary influenza virus infection in the absence of class I-restricted cytotoxic T cells. JImmunol. 1992;148(1):212-217.

65. Hardenberg G, van der Sluijs K, van der Poll T, Medema JP. APRIL affects antibody responses and early leukocyte infiltration, but not influenza A viral control. Mol Immunol. 2008;45(11):3050-3058.

66. Bossen C, et al. TACI, unlike BAFF-R, is solely activated by oligomeric BAFF and APRIL to support survival of activated B cells and plasmablasts. Blood. 2008;111(3):1004-1012.

67. Castigli E, et al. TACI is mutant in common variable immunodeficiency and IgA deficiency. Nat
Genet. 2005;37(8):829-834.

68. Salzer U, et al. Mutations in TNFRSF13B encoding TACI are associated with common variable immunodeficiency in humans. Nat Genet. 2005; 37(8):820-828

69. Salzer U, et al. Relevance of biallelic versus monoallelic TNFRSF13B mutations in distinguishing disease-causing from risk-increasing TNFRSF13B variants in antibody deficiency syndromes. Blood. 2009; 113(9):1967-1976.

70. Cunningham-Rundles C, Bodian C. Common variable immunodeficiency: clinical and immunological features of 248 patients. Clin Immunol. 1999; 92(1):34-48.

71. Yamada T, et al. Poly(I:C) induces BLyS-expression of airway fibroblasts through phosphatidylinositol 3-kinase. Cytokine. 2010;50(2):163-169.

72. Dubois B, et al. Dendritic cells enhance growth and differentiation of CD40-activated B lymphocytes. J Exp Med. 1997;185(5):941-951.

73. Geurtsvankessel CH, et al. Dendritic cells are crucial for maintenance of tertiary lymphoid structures in the lung of influenza virus-infected mice. J Exp Med. 2009;206(11):2339-2349.

74. Chu VT, et al. Eosinophils are required for the maintenance of plasma cells in the bone marrow. Nat Immunol. 2011;12(2):151-159.

75. Gomez MR, Talke Y, Goebel N, Hermann F, Reich B, Mack M. Basophils support the survival of plasma cells in mice. J Immunol. 2010;185(12):7180-7185.

76. Mozdzanowska K, Maiese K, Furchner M, Gerhard W. Treatment of influenza virus-infected SCID mice with nonneutralizing antibodies specific for the transmembrane proteins matrix 2 and neuraminidase reduces the pulmonary virus titer but fails to clear the infection. Virology. 1999;254(1):138-146.

77. Mozdzanowska K, Furchner M, Washko G, Mozdzanowski J, Gerhard W. A pulmonary influenza virus infection in SCID mice can be cured by treatment with hemagglutinin-specific antibodies that display very low virus-neutralizing activity in vitro. J Virol. 1997;71(6):4347-4355.

78. Wolf AI, et al. Plasmacytoid dendritic cells are dispensable during primary influenza virus infection. J Immunol. 2009;182(2):871-879.

79. Mozdzanowska K, Maiese K, Gerhard W. Th celldeficient mice control influenza virus infection more effectively than Th- and B cell-deficient mice: evidence for a Th-independent contribution by B cells to virus clearance. JImmunol. 2000;164(5):2635-2643.

80. User Bulletin \#2: ABI PRISM 7700 Sequence Detection System. Foster City, California, USA: PerkinElmer Corp; 1997.

81. Liang S, Mozdzanowska K, Palladino G, Gerhard W. Heterosubtypic immunity to influenza type A virus in mice. Effector mechanisms and their longevity. J Immunol. 1994;152(4):1653-1661. 